\title{
Claude Amiard-Triquet, Philip S. Rainbow, Michèle Roméo (Eds.): Tolerance to Environmental Contaminants
}

\author{
K. Jones
}

Published online: 31 August 2011

(C) Springer-Verlag 2011

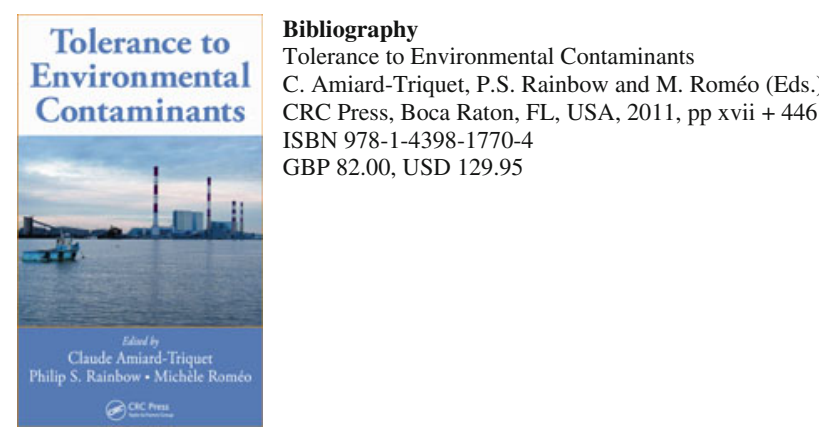

Toxicity is defined by the editors as effectively stress caused by temperature, oxygen, $\mathrm{pH}$, salinity, radiation and chemical contamination, usually in combination, plus the biotic factors of growth and reproduction. In contrast to its title and cover, which perhaps suggests it is limited to chemical contaminants only, by linking in these additional physical elements, the scope of the text is considerably widened.

Two mechanisms are defined to explain tolerance to toxic contaminants; an organism can build a resistance but which is not passed on genetically; the other where the genetic code is modified to allow future generations to tolerate ever increasing toxic levels. The primary purpose of the editors is to bring together experts in the field to define the mechanisms of how organisms acquire tolerance to different classes of environmental contaminants, and to determine the level at which they are overwhelmed. These general observations are then used to examine specific aspects of toleration to those contaminants that have a major impact on the modern world.

The species examined are very diverse, ranging from bacteria, fungi, phytoplankton, terrestrial flowering plants,

K. Jones $(\bowtie)$

Knutsford, Cheshire, UK and vertebrates (from fish to amphibians). Consequently, virtually every branch of the natural sciences is represented, making the potential readership considerable. Of very relevant interest is emergence of antibiotic-resistant bacteria, and insecticidal-resistance to DDT. Is resistance a function of DNA changes, changes in individual proteins, other structural changes, or a combination? These are the answers sought. If DNA is damaged then mutations occur, but frequently such changes have noxious effects that may include carcinogenesis. In other cases, mutation can give a selective advantage leading to a range of resistant genotypes. Most authors appear to accept that natural defence mechanisms in most species work well up to a certain level, but once above this level they become overwhelmed. In contrast, as analytical technology advanced and everlower levels of contaminants could be detected, so legislated levels of contaminants reduced in step. Eventually, the ability to detect part per billion levels created draconian legislation that closed manufacturing units, when in practice the levels detected were actually tolerable within the specific working environment.

Human beings, as top predator of both aquatic and terrestrial food chains are most at risk of eating bio-fortified foods, i.e. ones that have adapted to heavily contaminated environments and accumulated toxins (mainly metals) to a high level. Such events occuring regularly demonstrate that there is still much to learn. This compilation is far from complete (there is no mention of radiation effects), but nonetheless it is a very valuable addition to the literature. It defines the multidisciplinary approaches necessary to educate advanced students of toxicology and environmental science by describing the complexities involved, and how to utilise logic to prevent the accidental (and sometimes deliberate) poisoning of the general environment. 